\title{
RECOVERY CURVE AND CONDUCTION OF ACTION POTENTIALS IN THE URETER OF THE GUINEA-PIG
}

\author{
SANTA ICHIKAWA AND OSAMU IKEDA* \\ Department of Physiology, Showa Medical School, Shinagawa, Tokyo
}

As is well known, immediately after stimulation, excitable tissue possesses a stage of complete inexcitability, which is followed by a period of reduced excitability and then, sometimes, by a stage of hyper-excitability. The change of conduction velocity of excitation and the change of responsiveness also occur. Many works have been done on these problems using skeletal muscle and nerve. As smooth muscles have rather unstable excitability, quantitative research is difficult to do.

The muscle of ureter is visceral smooth muscle, but it is somewhat different from stomach and uterine muscles and the like. Its refractory phase is long as heart muscle and the musculature of ureter lacks of any summation of the mechanical responses $(1,2)$. And the ureter seems to be an excitable unit as a whole. It also has a pace-maker near kidney, so without this portion it is difficult to cause a spontaneous contraction. Because of these characteristics ureter has, the ureter of guinea-pig is used to obtain the recovery curve of its responsiveness. At the same time, some discussions are given here about the action potentials and the conduction of excitation in smooth muscle of the ureter.

\section{METHOD}

Ureters were removed from guinea-pigs anesthetized by sodium pentobarbital or ether and were kept in oxygenated Ringer-Krebs solution modified by Bülbring (3). The solution was of the following composition: $\mathrm{NaCl} 0.78 \mathrm{~g}$; $\mathrm{KCl} 0.035$ g.; $\mathrm{CaCl}_{2} 0.028$ g.; $\mathrm{NaHCO}_{3} 0.137$ g.; $\mathrm{NaH}_{2} \mathrm{PO}_{4} 0.0165$ g.; $\mathrm{MgCl}_{2} 0.029$ g. and dextrose $0.14 \mathrm{~g}$. in $100 \mathrm{ml}$ distilled water. The contraction of ureter muscle was recorded with an ink-writing oscillograph after the mechanoelectro transduce by a photo-electric tube. The ureter was mounted in a chamber and partly immersed in Ringer-Krebs solution. The ureter was fixed by a $V$ shaped slit at one end, the other end was tied with a silk thread and this thread was connected to a flag which controlled the light value to the photo-electric tube. Capillary calomel electrodes of about $2 \mathrm{~mm}$. diameter were arranged for recording the action potentials. To prevent the moving of

Received for publication June 1, 1959.

*开河三太, 洰汭 治 


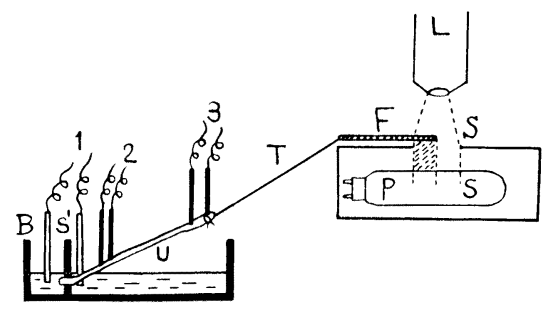

FIG. 1. Schematic representation of the experimental set-up. $B$ : mounted chamber, $S^{\prime}: V$ shaped slit which fixes the ureter, $U:$ ureter, $T$ : thread, $P S$ : photoelectric-tube, $L$ : lamp, $S$ : slit, $F$ : flag which modifies the amount of light coming into the photoelectric-tube, 1 : stimulating electrodes, 2 and 3 : leading electrodes, more details in text.

electrode by muscular contraction, very thin, flexible cotton wicks soaked in saline made connection with the electrode. For recording action potentials, the cotton wicks were placed on the surface of ureter suspended in the air and the electrical activity was led to the ink-writing oscillograph after directcoupled amplification. Two couples of electrodes were placed with $13 \mathrm{~mm}$. separation to each other in order to measure the conduction velocity (fig. 1). Rectangular currents or condenser discharges $(8 \mu \mathrm{F})$ were used as stimuli. The conditioning shock was approximately $1 \mathrm{~V}$ and the test shock was 5.8 Volt, because the rheobase of the ureter muscle was about 0.5 Volt. The chronaxie was estimated roughly $40-80 \mathrm{msec}$. To prevent the automatic contraction, about two thirds of the ureter from the vesical end was used and the chamber, in which the ureter was fixed, was immersed in a constant temperature bath of $32^{\circ} \mathrm{C}$. At $37^{\circ} \mathrm{C}$, sometimes the spontaneous contraction appeared even the pace-maker portion had been removed.

\section{RESULTS}

Conduction Velocity. The conduction velocity of action potential in the normal state was $2.41 \pm 0.91 \mathrm{~cm} / \mathrm{sec}$. (range $1.03-3.72 \mathrm{~cm} / \mathrm{sec}$.). This value is similar to that in the rat ureter (4) and of human ureter (5).

Recovery Curve of the Conduction Velocity. The conduction velocities were measured with excitation waves set up at variable stages of the relative refractory period. The recovery curve of the conduction velocity is shown in fig. 5 C. With a shock interval less than $5 \mathrm{sec}$., the test shock was ineffective to elicite an action potential conducted to the distal electrode. With increasing shock intervals, the conduction velocity recovers gradually and ten seconds after the conditioning shock the conduction velocity of action potential which is evoked by the test shock is about $50 \%$ of the normal. It recovers about $80 \%$ after $30 \mathrm{sec}$. and comletely recovers within $60 \mathrm{sec}$. In other words. if one wave follows another within about $60 \mathrm{sec}$., the speed of the second wave is lower than the first. Under high temperature $37^{\circ} \mathrm{C}$, the recovery process is accelerated, so that the conduction velocity of action potential by a test shock has shown the value of $90 \%$ of normal ten seconds after the conditioning shock, and the absolute refractory period ends within about 1.5 seconds. 
Recovery Curve of the Action Potentials. When the second stimulus is given during the relative refractory period, the height of action potential or the contraction wave evoked by that stimulus is smaller than that in the normal state and also the shape of action potential changes as shown in Fig. 2. The ratios of the heights of two action potentials elicited by the conditioning and test shocks give a recovery curve of the action potential height (fiigs. 3 and 5). The complete recovery of the action potential comes earlier than the recovery of the conduction velocity. Why the action potential height recovered faster than the conduction velocity? This was partly due to the technical limitation that the recovery curve of conduction velocity could not be obtained until the excitation wave was conducted to the distal electrode, but the recovery curve of action potential could be obtained only if it reached to the proximal electrode. In other words, an action potential evoked by a test shock within a time range of 3 to $5 \mathrm{sec}$. after the conditioning stimulus was conducted to proximal electrode, but not to the distal one. This fact sugests that, in the relative refractory period, the ureter conducts the excitation wave not only with a decreased velocity but decrementally.


FIG. 2. Records of action potentials of the ureter of guinea-pig induced by successive stimulations. Tracings from top are time (1 sec.), monophasic action potentials and diphasic action potentials. The monophasic action potentials were recorded from the distal electrode situated $20 \mathrm{~mm}$. apart from the stimulating electrode. The diphasic action potentials were recorded from the proximal electrode $7 \mathrm{~mm}$. away from stimulating electrode. $S_{1}$, conditioning shock; $S_{2}$, test shock. Details in text. 

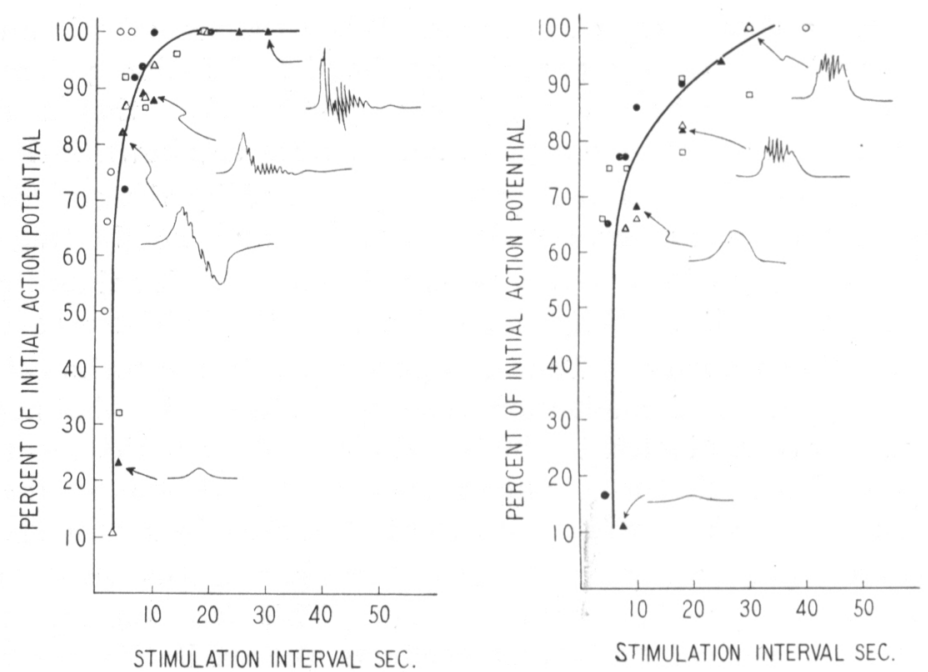

FIG. 3. Recovery curves of the action potentials led from the proximal electrode (left figure) and from the distal electrode (right figure). Inserted figures show the shape of action potentials. The same symbol for each experiment.

Recovery Curve of the Contraction Wave. Since usually leading electrodes were placed on muscle about $7 \mathrm{~mm}$. away from the stimulating point, it was difficult to examine the excitability at the stimulating point by recording action potentials. But since the ureter was tied with a silk thread at one end and the other end was fixed, even a local contraction would have been detected on the contraction curve (fig. 4). Therefore the excitability change at the stimulating point can roughly be examined by measuring the contraction height. Fig. 5- $B$ illustrates the relationship between the recovery of contractility and the interval of stimulation, namely, a recovery curve of the contraction wave. In this case the absolute refractory period was estimated
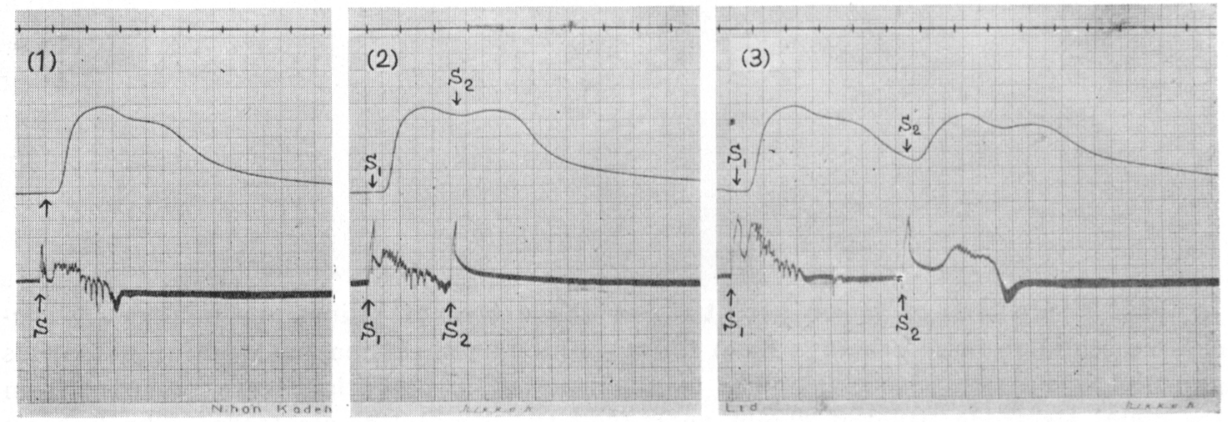

FIG. 4. Tracings from top are scale (1 sec.), contraction curves and diphasic action potentials. $S_{1}$, conditioning shock; $S_{2}$, test shock. 


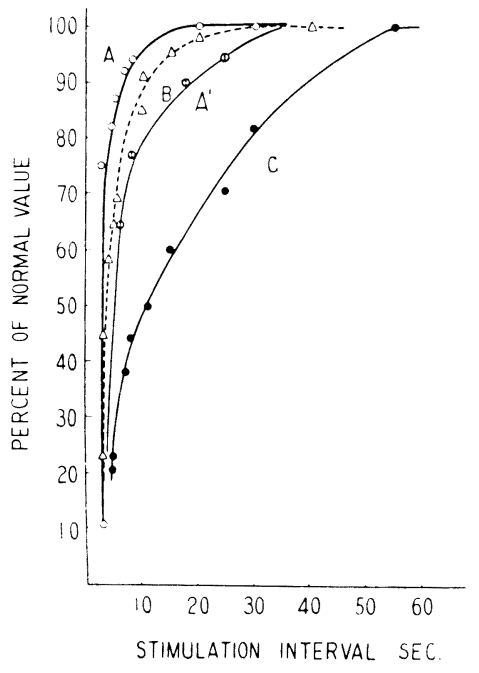

FIG. 5. Comparison of the recovery curves of action potential $(A)\left(A^{\prime}\right)$ with those of contraction $(B)$ and conduction velocity $(C)$. $A$ : recovery of action potential at proximal electrode. $A^{\prime}$ : at distal electrode.

about three seconds. The contraction height by a test shock which is given five seconds after the conditioning shock is $70 \%$ value of normal, after 20 seconds it recovers to about $95 \%$ and after 40 seconds it almost recovers completely. The recovery curves of responsiveness and the conduction velocity are compared in fig. 5 .

Patterns of Action Potentials. Monophasic action potentials were recorded with one end of the ureter tied and treated with $\mathrm{KCl}(4)$. The monophasic action potential has a sharp negative deflection and continuous plateau like wave with spike potentials. Sometimes the action potential shows an afterhyper-polarization (figs. 6-1 and 6-8). The number of these spike potentials are variable, but usually they are about ten, and the total duration of the action potential is about two or three seconds. The diphasic potentials of the ureter have a large and brief negative wave $(R)$ with spike deflections and a slow negative wave $(T)(2,4,6)$. The ureter of a guinea pig, but not normally in a cat, has a remarkable spike deflections $(2,7,8)$.

The shape of the diphasic action potential varies markedly with interelectrode separation. The typical pattern is found at inter-electrode distance of $2 \mathrm{~mm}$., while at about $8 \mathrm{~mm}$. the pattern consists of multiple irregular waves and at about $20-30 \mathrm{~mm}$. the pattern of a monophasic potential and the similar kind of pattern in the opposite direction appear successively (fig. 7). This phenomenon shows that the ureter has a unitary character $(6,9)$. Sometimes the ureter shows a long lasting strong contracture by a single shock stimulation. In this case the action potential has a long plateau like wave with spike deflections (fig 6-8). The patterns of action potentials are similar, regardless whether they are evoked spontaneously or artificially, that is, by electrical stimulation. This typical action potential indicates that the muscle contraction is a tetanic contraction in nature $(10,11)$ and the surface membranes of small smooth muscle cells in ureter are depolarized one after another (9).

The pattern of action potential remarkably varies at different stages in the refractory period. In an early stage of relative refractoriness, only small slow wave is obtained (fig. 2-2, lower curve) and with gradual recovery of the excitability, slow waves grow up and spike oscillations appear on them. When the interval of the conditioning and the test shocks is $25 \mathrm{sec}$., the form of 

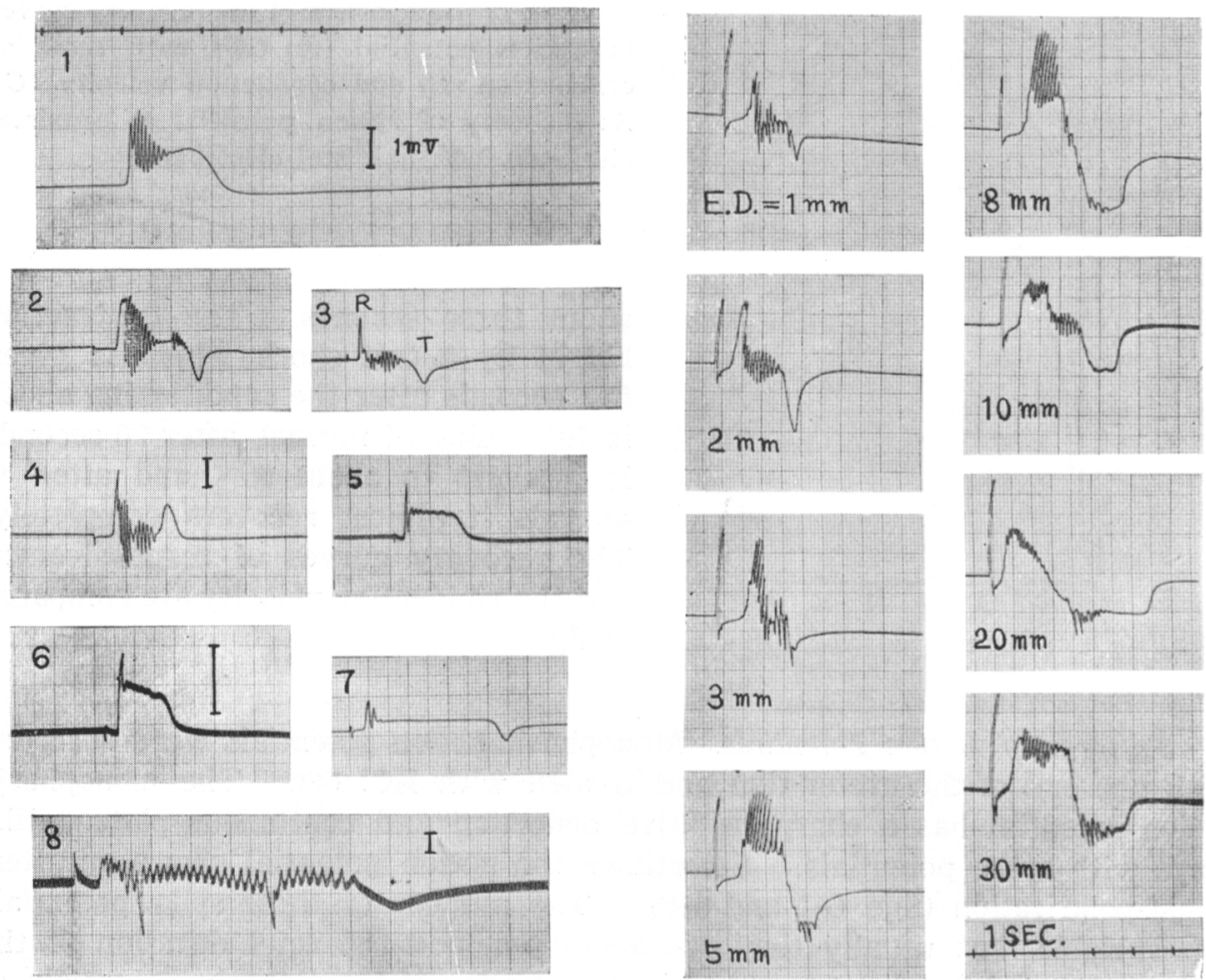

FIG. 6
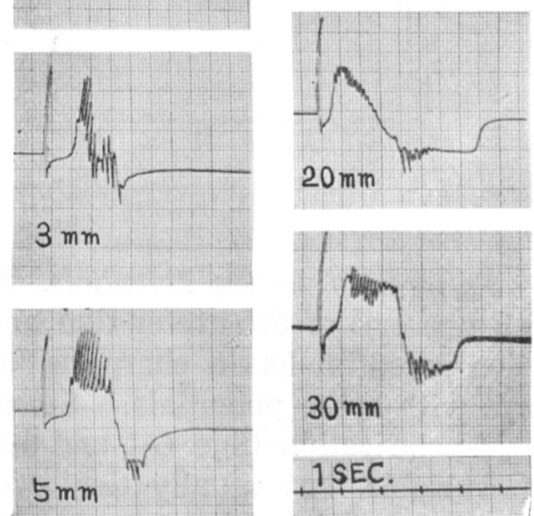

FIG. 7

FIG. 6. Various types of action potentials in the ureter of the guinea-pig. 1,5 and 6 , monophasic action potentials; 6 , action potential in the ureter of the cat.

FIG. 7. Effects of interelectrode separation on the shape of action potential.

potential evoked by the test shock is almost same as normal pattern (fig. 2-6). By the repetitive stimulation, according to the excitability state of the ureter, responses fall out periodically. When the interval of stimuli is 15 seconds, the responses regularly appear on trace $B$ in fig. $8-1,2,3$, but on trace $A$ small and large responses occur altenately. When the ureter is stimulated six times per minute the small slow waves are recorded occasionally. These large and small responses were also obtained by the repetitive stimulation of the ureter of a rat (4). The explanation of these phenomana is that the action potential is conducted decrementally in the muscle of ureter, when the muscle is in the relative refractory period.

\section{Effects of Drugs}

Acetylcholine. Acetylcholine $\left(10^{-6}\right)$ applied to the ureter prolongs the duration of depolarization phase and latent period. Spike potentials which appear on the plateau like wave become more frequent; namely, before the 

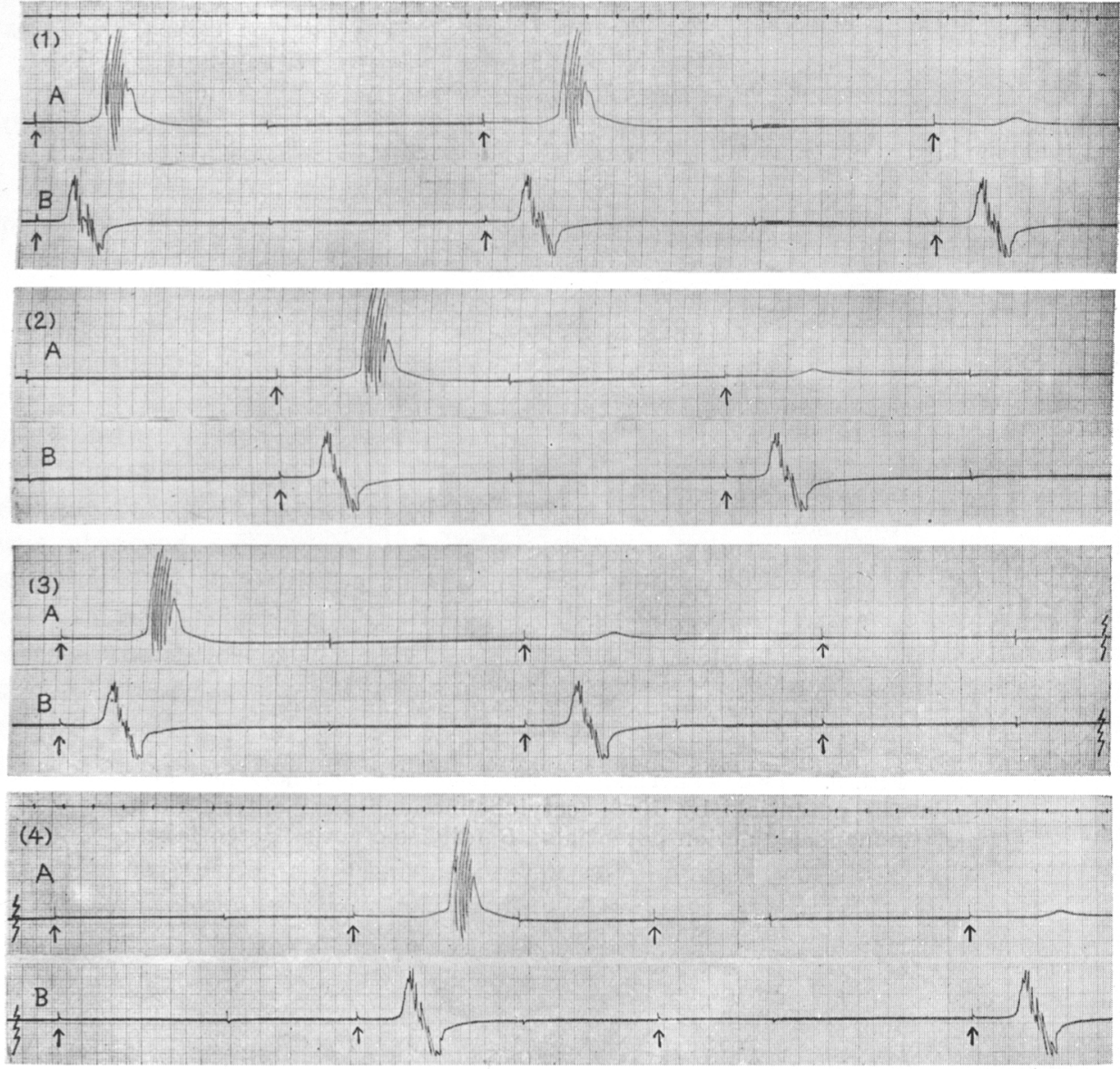

FIG. 8. Action potentials by repetitive stimulations. $A$ : record from distal electrode; $B$ : record from proximal electrode. $A$. in (2) and (3) shows the alternation between large and small responses. An arrow shows a stimulus. Time in scale 1 sec.

application the number of spikes are 20 but 30 seconds after the application it has increased to 26 , and also the depolarization phase is prolonged from 3.7 sec. to $4.5 \mathrm{sec}$. (Fig. 9). The action of acetylcholine is most remarkable 90 seconds after the application, and after that according to time lapse, the number of spikes and the duration of depolarization decreased. Sometimes. acetylcholine evokes automatic contractions.

Adrenaline. Adrenaline causes the prolongation of depolarization. When adrenaline $\left(10^{-4}\right)$ is applied to the muscle the depolarization phase elongates to 4.5 seconds after 1.5 seconds application. Before the application it was 2.1 sec. (fig. 9). In diphasic action potentials the interval of negative wave $R$ and slow positive wave $T$ is prolonged. The contraction waves have become stronger and the contraction period has also been elongated. But sometimes 

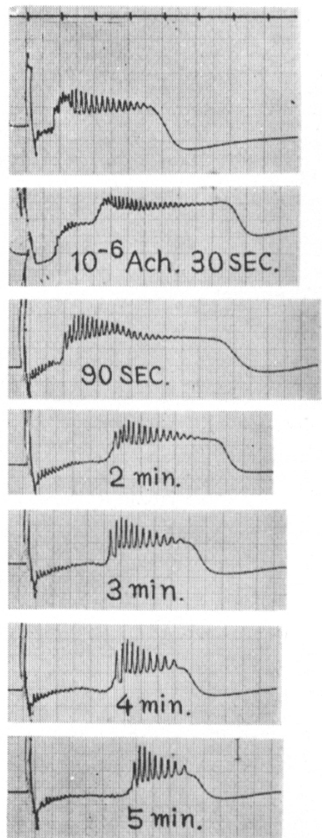
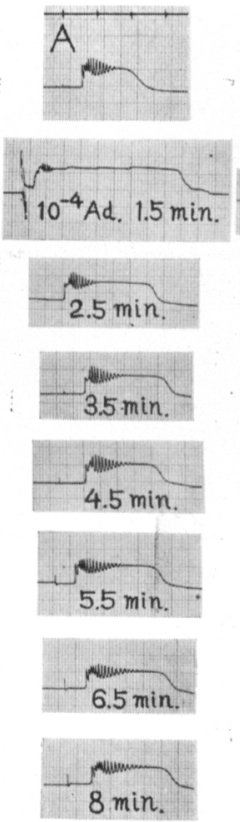
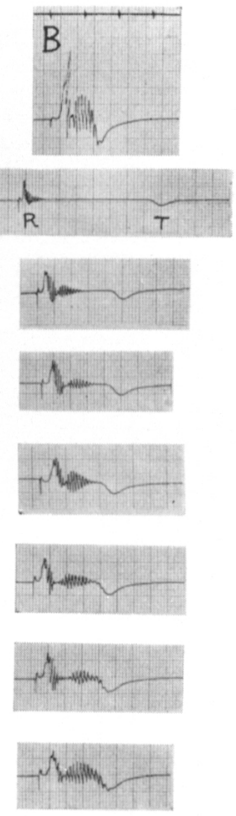

FIG. 9. Two experiments showing the prolongation of plateau potentials by $10^{-6}$ acetylcholine and $10^{-4}$ adrenaline. $A$ : monophasic action potentials; $B$ : diphasic action potentials.
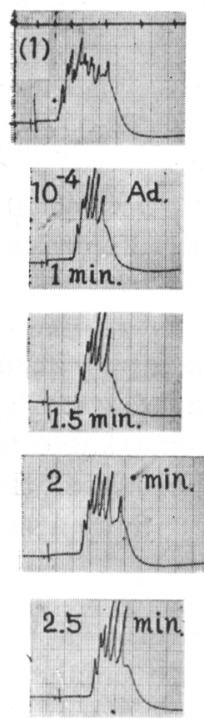

FIG. 10
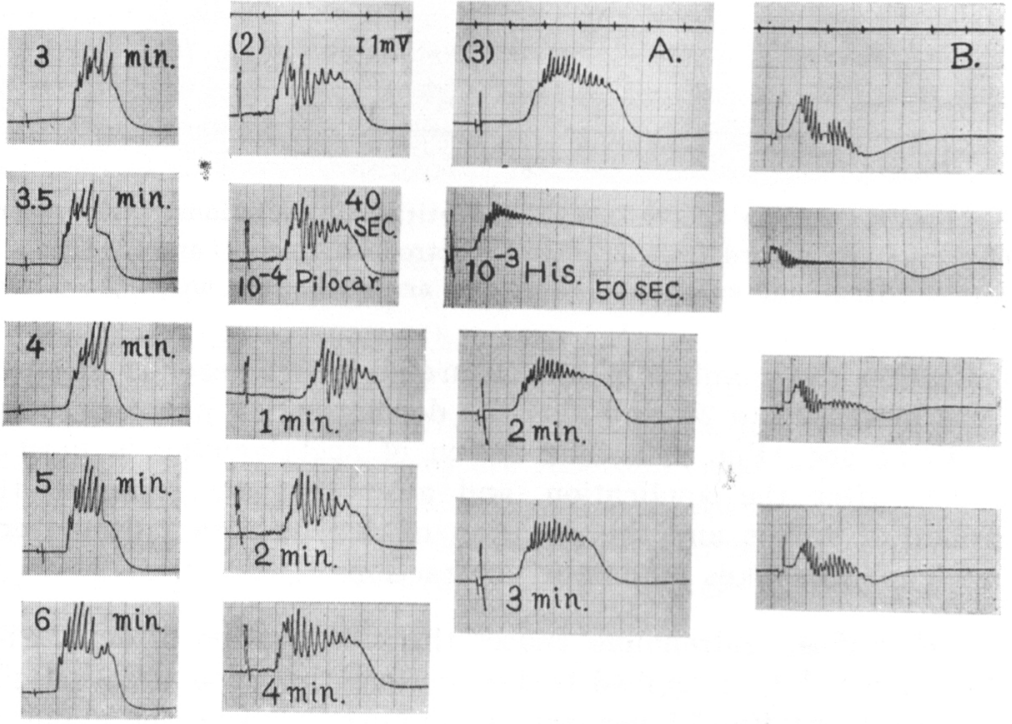

2: Effect of $10^{-4}$ pilocarpine hydrochloride on the shape of action potentials.

3: Effect of $10^{-3}$ histamine hydrochloride, showing the prolongation of plateau potentials. $A$ : monophasic action potentials; $B$ : diphasic action potentials. 
adrenaline has an opposite action, that is, the depolarization phase is reduced and the number of spike potentials decreases (fig. 10).

Pilocarpine. Pilocarpine $\left(10^{-4}\right)$ prolongs latent period but does not change the shape of action potential and the depolarization phase (fig. 10).

Histamine. As shown in fig. 10, histamine $\left(10^{-3}\right)$ prolongs the depolarization phase but the spike potentials which appear on the plateau are not influenced.

\section{DISCUSSION}

As stated above, the recovery of responses in the ureter such as action potentials or contraction waves is faster than that of the conduction velocity of excitation waves. Concerning the definition of the refractory period, Dawes (12) stated in details in his experiment using the cardiac muscle, but here we roughly referred to as absolute refractory period when no electrical variation was observed. Then in the ureter smooth muscle of the guinea pig, the absolute refractory period is estimated about three seconds, so within three seconds after the conditioning shock, no response appears even when the strong stimulation of 67.3 volt is applied. The relative refractory period varies and is estimated between 20 and 60 seconds at $32^{\circ} \mathrm{C}$. depending on whether action potentials, contraction waves or conduction velocity are observed. In $37^{\circ} \mathrm{C}$. absolute refractory period is 1.5 seconds and relative refractory period lasts five seconds.

The fact that in the refractory period the conduction velocity is slower than the normal state is known in the phrenic nerve of dog (13), ureter of rabbit and human ureter $(5,14)$. In human ureter, Butcher $(5)$ stated that absolute refractory period lasts about three seconds and during about five seconds after this period, the conduction velocity of contraction wave is slower than normal, namely "period of reduced wave velocity" appears. In our experiment not only the conduction velocity is slower during the refractory period but excitation is conducted decrememtally. In the experiments shown in figs. 2 and 4 both conditioning and test shocks were of above threshold and had enough strength, so that the local and conducted responses were not considered to be due to the strength of stimuli. The conduction with decrement has been noticed in the long body wall retractors of Thyone (15), ganglion* free circular muscle of cat intestine, especially at lateral conduction (16) and in hert muscle (17).

The patterns of action potentials also change in refractory period (14) (figs. 2 and 4 ). If the second stimulus is given early in the relative refractory period, the small slow wave is recorded. As mentioned above, this small wave is not coming from electrotonic spread.

Now some discussion will be given here about the conduction of excitation in smooth muscle of the ureter and the shape of action potential. In an earlier stage of relative refractory period the excitability is very low, so only a few muscle cell membranes are depolarized by a stimulation (18). When the excitability recovered more slightly, the number of firing cells increases 
but the electrical changes are largely short-circuited by extracellular fluid, so only small slow wave is led by large surface electrode. When this small slow wave grows up to a threshold, namely the number of firing cells increases to a limited value, this electrical variation activates the neighbouring inactive regions and induces a conducted all-or-none responses. This slow wave plays a trigger action on the conduction of excitation and the wave conducts decrementally through the muscle. It must be concluded that in the ureter the excitation conducts electrically from muscle fiber to muscle fiber (20) and because there are high resistance bridge-ephapse $(4,16)$. protoplasmic bridge $(1,9,19,20)$-the propagation of excitation is decrement.

The mechanisms of conduction in smooth muscle that deserve consideration are as follows.

1) A neural network or nerve fiber plays an important role in conduction as observed in Phascolosoma or Thyone $(15,21)$ (figs. 11-1 and 11-2).

2) Smooth muscle protoplasmic bridges resulting in a syncytium allowing conduction as in stomach, intestine, uterus, bladder and the like $19,10,22,23$, 24) (figs. 11-6 and 11-7).

3) Ephaptic conduction at overlapping muscle fibers as observed in ureter and intestine muscle by Prosser $(4,16)$ (fig. 11-5).

4) The release of an unknown substance by a contracting cell which activates its neighbouring cell. Butcher (14) stated that only histamine and antihistamine drugs effect change in action potential shape or conduction velocity, so the mechanism of conduction might be the release some histamine like substance by a contracting cell which stimulates contraction of neighbouring cells. But as mentioned above not only histamine but acetylcholine and adrenaline produce a change of action potential shape, especially adrenaline increases the contraction height and the excitability of the ureteral smooth muscle, so we are not quite ready to agree with Butcher.

5) Conduction by mechanical distortion of the neighbouring cell by the contracting one. Actually, the ureter muscle causes a repetitive contractions when the muscle stretched.
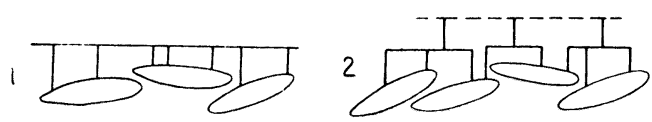

3
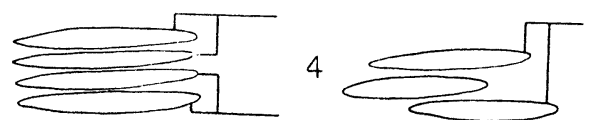

5
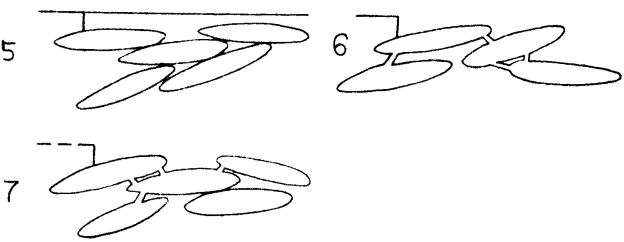

FIG. 11. Diagrams of hypothetical scheme of conduction system in smooth muscles. Solid line shows a nerve fiber.

1. Conduction from end to end by nerve fibers.

2. Muscle fibers innervated by short branching nerves.

3. Multiunit smooth muscle.

4. Semi-multiunit smooth muscle as observed in retractor muscle of Mytilus edulis. Ephaptic conduction may be considered.

5. Ephaptic conduction or humoral conduction.

6. Syncytium muscle innervated by nerves.

7. Syncytium muscle. 
SUMMARY

The recovery curve of excitability that follows an excitation in smooth muscle of the ureter of guinea-pig is examined. The responses such as action potentials and contractions of muscle recover earlier than the conduction velocity. In spite that the contraction curve has summation when a test shock is given in the relative refractory period, no action potentials are recorded from the leading electrode which is placed about $7 \mathrm{~mm}$. far from the stimulating point. When the excitability recovers slightly, the small slow potential change is recorded and after the complete recovery normal pattern of action potential is obtained. This fact shows that the excitation is conducted decrementally in smooth muscle when that muscle is in the state of refractoriness. Also from the patterns of action potentials recorded at several stages of relative refractory period, it was assumed that the excitation is conducted from cell to cell through protoplasmic bridges by the electrical variation. This variation is characterized by a slow potential wave. The effects of acetylcholine, adrenaline, histamine and pilocarpine on the patterns of action potentials are also examined.

\section{REFERENCES}

1. Bozler, E. Electric stimulation and conduction of excitation in smooth muscle. $A \boldsymbol{m}$. J. Physiol., 122: 614-623, 1938.

2. BOzLER, E. The action potentials of visceral smooth muscle. Am. J. Physiol., 124: 502-510, 1938.

3. Bülbring, E. Measurements of oxygen consumption in smooth muscle. J. Physiol. 122: 111-134, 1953.

4. Prosser, C. L., C. E. Smith ANd C. E. Melton. Conduction of action potentials in the ureter of the rat. Am. J. Physiol. 181: 651-660, 1955.

5. Butcher, H. R. JR. AND W. Sleator. JR. A study of the electrical activity of intact and partially mobilized human ureters. J. Urol. 73: 970-986, 1955.

6. BOzLER, E. The action potentials accompanying conducted responses in visceral smooth muscle. Am. J. Physiol. 136: 553-560, 1942.

7. GREVEN, K. Über Ruhe-und Aktionspotentiale der Glatten Muskulatur nach Untersuchungen mit Glaskapillarelektrode. Zeit. für Biol. 106: 1-15, 1953.

8. GREVEN, K. Zur Ableitung von Demarkationpotentialen und monophasischen Aktionsstromen an der Eingeweidemuskulatur. Pfiuger's Archiv. 267: 517-523, 1958.

9. ICHIKAWA, S. AND E. BOzLER. Monophasic and diphasic action potentials of the stomach. Am. J. Physiol. 182: 92-96, 1955.

10. Bozler, E. Conduction, automaticity and tonus of visceral muscles. Experientia. 4: 213-229, 1948.

11. Hoyle, G. AND J. Lowy. The paradox of mytilus muscle. A new interpretation. J. Exp. Biol 33: 295-310, 1956.

12. DAWES, G. S. AND J. R. VANE. The refractory period of atria isolated from mammalian hearts. J. Physiol. 132: 611-629, 1956.

13. GASSER, H. S. AND J. ERLANGER. The nature of conduction of an impulse in the relative refractory period. Am. J. Physiol. 73: 613-635, 1925.

14. Butcher, H. R. JR., W. Sleator. JR. AND W. P. Schmandt. A study of the peristaltic conduction mechanism in the canine ureter. J. Urol. 78: 221-231, 1957. 
15. Prosser, C. L. Activation of a non-propagating muscle in Thyone. J. Cell. and Comp. Physiol. 44: 247-253, 1954.

16. Prosser, C. L. AND N. SPERelakis. Transmission in ganglion-free circular muscle from the cat intestine. Am. J. Physiol. 187: 536-545, 1956.

17. KAO, C. Y. AND B. F. Hoffman. Graded and decremental response in heart muscle fibers. Am. J. Physiol. 194: 187-196, 1958.

18. BURNSTOCK, G. The effects of acetylcholine on membrane potential, spike frequency, conduction velocity and excitability in the taenia coli of the guinea-pig. J. Physiol. 143: 165-182, 1958.

19. ThAEMERT, J. C. Intercellular bridge as protoplasmic anastomoses between smooth muscle cells. J. Biophy. and Bioche. Cytology. 6: 67-70, 1959.

20. NishiokA, K. Deformation of the transmembrane action potential of the uterine smooth muscle caused by interaction in function between adjacent fibers. Kagoshima Med. J. 32: 391-402, 1959 (in Japanese).

21. Prosser, C. L. ANd C. E. Melton. Nervous conduction in smooth muscle of Phascolosoma proboscis retractors. J. Cell. and Comp. Physiol. 44: 255-275, 1954.

22. BülbRING, E. Correlation between membrane potential, spike discharge and tension in smooth muscle. J. Physiol. 128: 200-221, 1955.

23. BÜLBRING, E. Changes in configuration of spontaneously discharged spike potentials from smooth muscle of the guinea-pig's taenia coli. The effect of electrotonic currents and of adrenaline, acetylcholine and histamine. J. Physiol. 135: 412-425, 1957.

24. BRUNNe, H. F. UND H. Kotowski. Die Erregungsleitung in der glatten Muskulatur des Meerschweinchen-Dickdarmes. Pfiiger's Archiv. 262: 484-493, 1956. 